years of treatment (Revicki et al, 1990; Drummond \& Davies, 1993). It is this evidence that should be used to educate managers and purchasers to demand that patients who suffer from treatment resistant schizophrenia recetve clozapine as part of an overall treatment package for this disabling illness.

At present the prescription of clozapine is restricted to 20 patients in our district. The Department of Health, the BMA and the Royal College of Psychiatrists have all condemned this rationing of care. One possible solution to this restriction would be to vary the price of inpatient and out-patient care to take into consideration the cost of clozapine. We are looking into this possibility.

DRUMMOND, L. M. \& DAVIES, M. F. (1993) Assessment of costs and benefits of drug therapy for treatment-resistant schizophrenia. British Joumal of Psychiatry, 162, 3842.

KING, D. J. \& Mrus, P. J. (1993) Clozapine: the Hollywell experience with the first 24 patients. Irish Journal of Psychological Medicine, 2, 205-207.

MELTZER, H. Y. (1992) Some personal recommendations about using Clozarll. Clozarl Newsletter, 4, 1-3.

REVICK, D. A., LUCE, B. R., WeSCHLER, J. M., BROWN, R. E. \& ADLER, M. A. (1990) Cost-effectiveness of clozapine for treatment-resistant schizophrenia patients. Hospital and Community Psychiatry, 41. 850-854.

Alice Seabourne and Christopher S. Thomas, South Manchester University NHS Trust, Withington Hospital, West Didsbury, Manchester M20 2LR

\section{Antidepressant prescribing by GPs}

Sir: R. J. Thompson's study on antidepressant prescribing among general practitioner referrals to a community mental health unit in New Zealand (Psychiatric Bulletin, 1994, 18, 461-462) and K. R. Linsley's comment (Psychiatric Bulletin, 1994, 18, 703) suggested that sub-therapeutic prescribing might have to do with longer intervals between consultations related to the fees New Zealand residents have to pay to see their GP.

My survey of antidepressant prescribing among GPs referring clients to a community mental health centre in Keighley suggests that sub-therapeutic prescribing is also common in the UK where residents do not pay consultation fees (albeit many pay a fee per prescription). To determine whether GPs prescribe antidepressants in adequate dosage once they have established an indication for their use, I collected data from referral letters of 100 consecutive clients referred for depression while on antidepressants. Where dosage was not mentioned, the GP practice was contacted to clarify the dose at the time of referral.

The referrals consisted of $26.6 \%$ of a total of 376 referrals by GPs received during 18 months from April 1993. Seventy-six were women aged 17-61, and 24 men aged 22-55. Just over half were on tricyclic and related antidepressants of which the most widely prescribed was dothiepin (34/52). Applying the consensus statement of Paykel et al (1992), $75 \%(39 / 52)$ of clients on tricyclics were on sub-therapeutic doses (i.e. less than $125 \mathrm{mg}$ daily), $69.2 \%(36 / 52)$ taking $75 \mathrm{mg}$ or less. This is well after the launching of the Defeat Depression campaign, a disappointing result.

In stark contrast to Dr Thompson's sample. where few were prescribed selective serotonin re-uptake inhibitors (SSRIs), almost half of clients in Keighley were on these drugs, mostly fluoxetine (32/48). According to guidelines of manufacturers, $87.5 \%(42 / 48)$ of clients on SSRIs were on the minimum dose. Although this dose is said to be therapeutic, experience in psychiatric practice suggests that higher doses are frequently needed. It may be that GPs could treat many patients more effectively using higher doses of SSRIs.

PAYkel, E. S., Prest, R. G. et al (1992) Recognition and management in general practice: consensus statement. Brttish Medical Joumal, 305, 1198-1202.

ERIK VAN DEN BRINK, Ingrow Centre for Community Mental Health, 200 South Street, Keighley, West Yorkshire BD21 1BB

\section{Leave for restricted patients}

Sir: A letter dated 5 September 1994 and addressed to "All responsible medical officers in special hospitals, secure units and other psychiatric hospitals" from the Head of C3 Division at the Home Office indicates that the Secretary of State has "decided that ... he will normally no longer give consent for restricted patients to have escorted or unescorted leave of absence from hospital for holidays or holiday-type activities".

I read this with concern and when I discussed it with my immediate colleagues I found that this concern was shared. I would be interested in wider views of this (especially from forensic psychiatrists) and whether the forensic section of the College has any views. 